\title{
LA REALIDAD BOLIVIANA EN LA NARRATIVA DE JESUS LARA
}

\author{
POR \\ WILLY O. MUNTOZ \\ Kent State University
}

En este artículo nos limitaremos a analizar la narrativa indigenista de Jesús Lara, a través de la cual puede reconstruirse la trayectoria vital de los indios del valle de Cochabamba. Para lograr este propósito, ordenaremos el contenido novelístico con arreglo al acontecer cronológico de la historia de Bolivia antes que regirnos por la fecha de la publicación de sus libros. El contenido narrativo-histórico incluye el feudalismo durante la República, la participación del indio en la guerra del Chaco, la revolución nacional y termina con la etapa post-revolucionaria o la contrarrevolución. Por el tono de su contenido, esta novelística puede dividirse en dos partes, que corresponden, primero, a la época prerrevolucionaria, y segundo, a la revolución nacional misma, en 1952, y las consecuencias directas que afectan la vida del indio. Las novelas de Lara caen dentro de las líneas generales del indigenismo, en el sentido de que éstas exponen las costumbres y aspiraciones del indio, denuncian la explotación de que es objeto y muestran la dualidad cultural y la bipolaridad socioeconómica que cohíbe su desarrollo 1.

Lara se suscribe a los dictámenes de la tesis de Mariátegui, que sostiene que la cuestión indígena arranca del problema de la propiedad de la tierra y de la subsistencia de los gamonales. El gamonalismo no sólo designa una categoría social y económica, la de los latifundistas, sino que constituye todo un sistema que comprende una larga jerarquía de funcionarios intermedios ${ }^{2}$. En el caso de Bolivia, el ciclo de explotación está construido en base de una distribución piramidal del poder, en cuya cúspide descansa

${ }^{1}$ Eugenio Chang-Rodríguez, «E1 indigenismo pertuano y Mariátegui», en Revista Iberoamericana, 50, 127 (abril-junio 1984), p. 367.

${ }^{2}$ José Carlos Mariátegui, Siete ensayos de interpretación de la realidad peruana (Lima: Empresa Editora Amauta, 10." ed., 1965), pp. 33-34. 
la figura del patrón o terrateniente. En su ausencia toma su lugar el mayordomo, secundado por los kurakas, autoridades subalternas en los pegujales, y en la base se hallan los indios, los que trabajan y hacen producir la tierra. La gradación del tinte de la piel de esta pirámide corrobora la conclusión de Américo Ferrari de que el problema del indio es más un problema social que étnico, más económico que racial ${ }^{3}$.

En la primera parte de su narrativa, Lara nos sitúa precisamente en el momento histórico del declinar de las comunidades indígenas, con el consiguiente auge del latifundio. En estas circunstancias, el indio, por su condición de siervo, al ser privado de la tenencia de la tierra y excluido de los beneficios de su principal medio de producción, es explotado directamente por el patrón, quien se aprovecha de la gran cantidad de mano de obra que no tiene otra clase de ocupación. Consecuentemente, el amo no siente la necesidad de mejorar las condiciones de trabajo, ni de mecanizar la agricultura, puesto que el esfuerzo gratuito del colono le reporta una cuantiosa ganancia. En ausencia de los amos, el mayordomo es el encargado de llevar adelante la producción de la tierra. Lara, en el delineamiento de la figura del mayordomo, utiliza rasgos comunes que hacen de este personaje un «tipo» ${ }^{4}$. En términos generales, el mayordomo es un cholo semiletrado y bilingüe que viene del pueblo o de la ciudad, donde aprendió las maneras de los patrones, a quienes trata de emular, al mismo tiempo que se esfuerza por despreciar al indio, olvidando que allí se encuentra su verdadero origen. Su afán arribista y el deseo de complacer a los patrones hacen de él un verdadero tirano de sus hermanos de sangre. Montado en su cabalgadura, calzado con botas de cuero e investido con un látigo, vigila severo, desde las alturas, la prolongación de la condición servil del indio. Puesto que el poder marcha mano a mano con la afluencia económica, el mayordomo cuida igualmente de incrementar su fortuna personal. Para lograr su objetivo se aprovecha de la postración del indio, a quien hace víctima de una serie de negocios ilícitos que lo atan económicamente al lugar de producción.

Para mantener el sistema opresivo intacto, el terrateniente cuenta con el sólido apoyo de las agencias del gobierno. Vale decir, el indio no sólo es subyugado por individuos, sino también por organismos como la Policía, el Ejército, todo el sistema jurídico, al que debe añadirse la Iglesia. En su

${ }^{3}$ Américo Ferrari, «El concepto de indio y la cuestión racial en el Perú en los 'Siete ensayos' de José Carlos Mariáteguì, en Revista Iberoamericana, 50, 127 (abril-junio 1984), p. 401.

${ }^{4}$ En su primera novela, Surumi (1943), Jesús Lara narra las maniobras económicas y tiranizantes del mayordomo Manelsinu y de sus asaltos sexuales a las mozas indias (La Paz: Los Amigos del Libro, 3. ${ }^{2}$ ed., 1973). 
novela Yanakuna ${ }^{5}$ es donde mejor puede apreciarse cómo las leyes coadyuvan a la explotación del indio. Wayra, con su t'inka, el pago en especie, y su hija maltrecha por el asalto sexual que sufriera a manos del hijo del patrón, realiza una peregrinación en busca de justicia, pero choca contra una barrera infranqueable, puesto que ningún abogado atiende a los indios. Entonces Wayra se da cuenta de que «no sólo las riquezas, sino también la justicia y las leyes, eran patrimonio exclusivo de ellos» (p. 309), de los qhapajkuna, que formaban una casta sólida y terrible. Pero cuán presto a castigar se halla el brazo de la ley cuando es llamado para sofocar cualquier intento de rebelión indígena. Ante este sistema represivo, la Iglesia, por medio de sus curas de pueblo, predica la resignación y el sufrimiento como caminos para obtener la gloria eterna, además de desangrar los magros ahorros del indio al obligarlo a cumplir con una serie de ritos religiosos en los que gasta sus últimos centavos.

Surumi, Yanakuna y la primera parte de Suinapura, que se suceden históricamente antes de la guerra del Chaco (1932-1935), abundan en los pormenores temáticos de la literatura indigenista al estilo de Aves sin nido, o Raza de bronce, o Huasipungo. Son novelas donde se entreteje la enconada explotación del indio y muestran la realidad del feudalismo agrario boliviano, que crea una división de clases e impide el desarrollo cultural de un pueblo netamente agricultor. Bolivia recién se daría cuenta de su retraso durante la guerra del Chaco, elemento catalizador que contribuirá al despertar de la conciencia nacional ${ }^{6}$ y a la modernización del país. El intelectual que asiste a la contienda bélica se siente como un extraño en su país al comenzar a percatarse de la diversa gradación étnica

${ }^{5}$ Jesús Lara, Yanakuna (La Paz: Los Amigos del Libro, 1952, 3. . ed., 1974).

${ }^{6}$ El historiador inglés Murdo J. Macleod llega a la conclusión de que hasta los años antes del conflicto bélico a los escritores de este país andino no les interesaba si «Bolivia could remain feudal, cast-ridden, backwards and torn by fictional strifes. That the indians had little or no place in national life while he constituted the majority of the population did not seem to disurb them». Bolivia and Its Social Literature Before and After the Chaco War (Diss. University of Florida, 1962), pp. 84 . 85. A pesar de que hay algo de verdad en esta aseveración, no se puede dejar de notar la existencia ya de novelas como Raza de bronce (1915), de Alcides Arguedas, o el ensayo de Franz Tamayo sobre La creación de la pedagogía nacional (1910), donde se augura al indio como el gran depositario de la energía boliviana. Para seguir en apretada síntesis las teorías racistas de este país hasta antes de la guerra del Chaco, véase el artículo de José Ortega, «Indigenismo y alienación en las letras bolivianas», en Chasqui, 6, 3 (mayo 1977), especialmente pp. 27-29. Para ver el tratamiento del indio en el teatro durante este período, véase el capítulo «"La huerta': Acercamiento al problema del indio», en mi libro Teatro boliviano contemporáneo (La Paz: Ediciones Casa Municipal de la Cultura «Franz Tamayo», 1981), pp. 41-58. 
boliviana o de lo inexpugnable de su geografía. Su alienación se magnifica al percibir la incapacidad logística de los conductores de la nación y constatar los desastrosos resultados del sistema feudal. El choque anímico revelatorio fue tal, que dedicaría el resto de su vida para escribirlo ${ }^{7}$. Jesús Lara tenía ya plena conciencia de la situación del indio, puesto que convivió con él toda su vida, y como José María Arguedas, habló más temprano el quechua que el castellano, que lo aprendió en la escuela primaria. Pero en las arenas del Chaco confirma su vocación como escritor comprometido en defensa de los indios. Su reacción no se deja esperar: a los dos años del cese de fuego publica Repete. Diario de un hombre que fue a la guerra del Chaco (1937) ${ }^{8}$. Allí transcribe sus impresiones de guerra, opiniones que son reiteradas una y otra vez en obras de ficción como Sujnapura ${ }^{9}$ y Surumi. De estas novelas puede concluirse que la guerra del Chaco se había hecho para los indios y los obreros. Los parias, que nunca gozaron de derecho alguno, ahora se ven abrumados por obligaciones; la patria, que nunca les dio nada, les obliga ahora a ofrendar sus vidas en defensa de la soberanía nacional. Una vez que son diezmados, los adolescentes y los ancianos, aquéllos que por su temprana o avanzada edad no pertenecen a aquel anfiteatro macabro, son llevados al frente, a seguir rindiendo su vida para una causa que desconocen y no entienden. Mientras que los burgueses, que antes vendían salud, ahora forman legiones de hombres aquejados por las más diversas enfermedades. En el frente, el indio comparte con gentes de otros rincones de Bolivia, aprende un poco de castellano y convive con algunos oficiales, de los que asimila algo de su comportamiento.

${ }^{7}$ Fernando Díez de Medina, en su Literatura boliviana, dice que el escritor de la novela de protesta social, que él denomina «escuela vernacular», vuelve los ojos para exponer los males, destruir el anacrónico sistema feudal y proporcionar soluciones viables para la modernización de Bolivia, al mismo tiempo que busca la exaltación de lo propio en una sincera rebeldía: «Es como si el boliviano hubiera despertado al conocimiento de sí mismo» (La Paz: Libro Editor Alfonso Tejerina, 1953), pp. 330-331. Véase también Jorge Siles Salinas, La literatura boliviana de la guerra del Chaco (La Paz: Ediciones de la Universidad Católica Boliviana, 1969).

${ }^{8}$ Jesús Lara, Repete (Cochabamba: Editorial Carlos Canelas, 2. ed., 1937).

${ }^{9}$ La segunda parte de Sujnapura, denominada «La derrama», presenta al lector los múltiples acontecimientos que les tocó vivir a los «repetes», a los conscriptos indios. Estos pasajes constituyen, en nuestra opinión, uno de los más logrados de la narrativa de este escritor. Con un estilo de frases cortas y precisas, el ojo avizor del narrador se traslada de un lugar a otro, a velocidad vertiginosa, para mostrarnos, en cada oración, un punto de vista o perspectiva diferente de la lucha, con el propósito de presentar al lector las mil y una acciones que simultáneamente se suceden en el fragor del combate. Con un estilo barroco de tupido detalle, consigue Lara la pintura de un cuadro tan vivo que el lector se siente en medio de ese laberinto de balas (La Paz: Los Amigos del Libro, 1971). 
El ex combatiente que sale del Chaco - blanco, indio o mestizo- regresa transformado. Sin embargo, sería una exageración afirmar que el indio adquiere una conciencia de clase como consecuencia de esta contienda bélica; pero sí se puede asegurar que a su regreso al campo o al incorporarse a la colmena citadina o al emigrar a las minas, el indio lleva consigo una experiencia que no se le borrará hasta el fin de sus días.

Los errores y horrores de la guerra no terminan allá, en el escenario bélico, sino que continúan hasta después del retorno a la patria. Surumi nos hace conocer el regreso de las tropas después del cese de fuego y lo que ocurre inmediatamente después. Los políticos, astutamente, se dan cuenta del poder latente que los ex combatientes tienen e intentan incorporarlos en partidos políticos como un apoyo e impulso en su loca carrera hacia el poder. Wáskar Puma observa que las dolorosas lecciones de guerra son pronto sustituidas por la ambición de unos cuantos oportunistas. Entonces, para mantener viva la toma de conciencia, este indio aculturizado se embarca en una cruzada revolucionaria. Como él, doce camaradas se esparcen por todo el territorio nacional para forjar una nueva sociedad que reivindique a los oprimidos. De esta manera, Surumi apunta a la futura trilogía.

Los eventos históricos, después de la conclusión de la guerra del Cha$c o$, tienen una importancia capital, puesto que representan un período de gestación de grandes cambios sociopolíticos que culminarán con la revolución nacional de 1952, y que explica, en cierto modo, la manera de ser de la Bolivia de hoy. La situación económica del país en los años precedentes a la revolución nacional se halla contenida en el «Informe Keenleyside» - director de una misión de las Naciones Unidas-, que constituye el documento de evaluación más valioso para conocer la realidad económica y social boliviana hasta el año 1950. Este, en sus partes más sobresalientes, anota:

La agricultura está atrasada y hay que importar alimentos y materias primas que podrían producirse en el país. La industria minera ha llegado a un punto en que, a menos que nazca la confianza y pueda invertirse considerable capital, parece estar al borde de una grave decadencia. El petróleo y la energía hidroeléctrica no pueden ser desarrollados suficientemente, porque los recursos disponibles no han sido todavía estudiados. Gran parte de la población es analfabeta y enfermiza, y la mortalidad infantil es aterradoramente alta ${ }^{10}$.

10 Mariano Baptista Gumucio, Historia contemporánea de Bolivia: 1930-1978 (La Paz: Gisbert y Compañía, 1978), p. 555. 
Este es el fondo histórico sobre el cual se desarrolla el argumento de las novelas que hemos denominado «trilogía de la revolución agraria». Esta segunda parte de su narrativa está compuesta por Yawarninchij (Nuestra sangre), que aparece en 1959, y presenta al indio en espera de la posesión de la tierra; seguida por Sinchikay (E1 valor), en 1962, o la toma de la tierra por aquéllos que la cultivan; para terminar con Llalliypacha (Tiempo de vencer), en 1965, en el que el campesinado se apresta a defender su tierra. La trilogía tiene como base la comunidad de Saipurenda, la que se ve transformada físicamente a medida que se suceden las tres etapas de la revolución agraria. De este pueblo salen los personajes, que pasan de una novela a otra en su quehacer revolucionario, y a él regresan para aportar sus conocimientos adquiridos. Como tal, esta comunidad se convierte en un símbolo de autonomía, en un estandarte de lucha.

Yawarninchij ${ }^{11}$, la primera estampa de la revolución, relata la situación del agro en los años inmediatamente anteriores a la revolución de 1952; incluye la promulgación de la reforma agraria y termina el año 1955, más o menos. Al subir al poder el Movimiento Nacionalista Revolucionario (MNR), para erigirse como un gobierno pro proletario, nacionaliza las minas ${ }^{12}$. En el campo se rumorea este hecho y corre la voz de que asimismo existe un estudio para realizar la reforma agraria. Sin embargo, el indio recibe estas noticias con una mezcla de optimismo e incredulidad, escepticismo reflejado en diálogos como: «De modo que los kapajkuna serían despojados de sus haciendas y ellas pasarían a manos de los indios; los indios, de siervos que eran, se convertirían en dueños de las tierras» (p. 72).

A la par de estos rumores aparece en el campo un individuo nocturno que se hace llamar el Minero. Por medio de este personaje, el autor manifiesta su parecer en torno al problema del indio y lo hace a través de pasajes que adquieren todas las características de ensayos, pero que están perfectamente incorporados a la acción de la novela, además de que son emitidos por boca de este personaje. El propósito del Minero es sacar al

${ }^{11}$ Jesús Lara, Yawarninchij (La Paz: Los Amigos del Libro, 1959, 3.a ed., 1974). Futuras acotaciones de esta novela aparecerán en el texto con la página entre paréntesis.

${ }^{12}$ Para estudiar los antecedentes de la nacionalización de las minas y de la Reforma Agraria, véase el acápite sobre la «Tesis de Pulacayo», en el libro de Liborio Justo Bolivia: La revolución derrotada (Cochabamba: Editorial Serrano, 1967), pp. 156 y ss. Sobre el programa del gobierno del MNR, véase Alfredo G. Candia, Bolivia: Un experimento comunista en la América (La Paz: n. p., 1954), pp. 42 y ss. Para entender los alcances de la reforma agraria y la forma como se implantó, léase a Arturo Urquidi, El feudalismo en América y la reforma agraria boliviana (Cochabamba: Imprenta Universitaria, 1966). 
indio de su estado de postración y cambiar su psicología de siervo ignorante, por lo que les recalca que el indio es tan ser humano como su opresor, y como él necesita alimentarse y cultivar su inteligencia. Para lograr estos derechos y muy especialmente la tierra, insta a su pueblo a la acción directa; de ahí que las actividades de los pobladores de Saipurenda constituirán un experimento controlado y revolucionario.

Como el tema central de la trilogía es la obtención de la tierra, Lara narra minuciosamente las consecuencias económicas, sociales y políticas de la reforma agraria. Para empezar, se sucede un cambio en la distribución del poder en el campo: cuando los terratenientes dejan sus haciendas, al ponerse en marcha los mecanismos de la reforma agraria, su autoridad es sustituida por la emergencia de un nuevo personaje histórico en el valle cochabambino: se trata del cacique. Ellos llegan a ser los pequeños dictadores de sus respectivos predios, a pesar de que obedecen a consignas políticas ajenas a los intereses de sus subalternos ${ }^{13}$.

Históricamente, la reforma agraria, en un primer instante, representa un triunfo para la clase campesina - vocablo introducido precisamente a raíz de los cambios sucedidos-: ya no eran indios, sino campesinos. Entre las consecuencias inmediatas se encuentra la desaparición de la clase patronal, que emigra a las ciudades. La supresión de los patrones termina con la explotación laboral del campesino y la vejación personal de que él y su familia eran objeto; junto con los patrones se acaban los servicios gratuitos del pongueaje y del mitanaje y cualquier otra forma de trabajo no remunerado; se anulan todas las deudas de los indios al patrón, puesto que éstas fueron consecuencia de uno de los tantos ardides empleados para dependizar a los colonos. Finalmente, la tierra pasa a ser de los campesinos. Este acápite, dentro de la ficción y en la realidad, resulta una medida contraproducente por la forma en que fue llevada a cabo.

La Reforma Agraria tardó demasiado en ser puesta en práctica, por lo que Lara opina que tanto la Nacionalización de las Minas como la Reforma Agraria fueron más que todo medidas políticas de apaciguamiento del pueblo destinadas a conseguir el apoyo popular y no para mejorar las condi-

${ }^{13}$ La nueva clase directriz del país utiliza a estos dirigentes campesinos como esbirros para mantener su control en el campo. Lara se ciñe a esta función cuando define a los caciques, indios acholados, como «sujetos más o menos despiertos que, cansados de la miseria del pejugal, se divorciaron del arado y de la coca y desctbrieron que oprimir a la gente era más productivo que uncir los bueyes». Sinchikay. (La Paz: Los Amigos del Libro, 1962, 2. ${ }^{a}$ ed., 1976), p. 116. Futuras acotaciones de esta novela aparecerán en el texto con la página entre paréntesis. Mariano Baptista Gumucio provee una estimación del impacto histórico de estos dirigentes campesinos en su Historia contemporánea de Bolivia, p. 585. 
ciones de vida de los obreros y de los campesinos. En el campo se viven momentos de incertidumbre y confusión al no ser los indios los legítimos dueños de la tierra. Razón por la cual surge una serie de preguntas como ¿son los indios dueños de su pegujal?, ¿podían repartirse las tierras de la hacienda del antiguo amo?, ¿deberían sembrar la tierra?, y si lo hacen, ¿de quién serían las cosechas? Históricamente, el monto que el gobierno dispuso para efectuar la reforma agraria fue uno de los más bajos destinados a cualquier agencia estatal: constituía el 0,6 por 100 del erario nacional ${ }^{14}$. Por esta razón, los empleados que se hallaban abocados a la repartición de títulos, para compensar sus bajos sueldos, dilataban innecesariamente las gestiones para extorsionar a los que aspiraban a la posesión de un pedazo de tierra. La aparición de los abogados para los juicios de afectación comprometió seriamente la paupérrima economía de los indios. «El abogado era especialista en esta clase de juicios, pero aún más en el cobro de los honorarios», sentencia Lara en Yawarninchij.

Mientras el campesino espera que se le reparta la tierra, los antiguos terratenientes, por medio de hábiles abogados y de ardides legalistas, procuran recuperar la tierra. Los leguleyos alegan que las tierras de sus clientes no eran «latifundios improductivos», sino «empresas agrícolas», o como se las define en el artículo 11 de la Reforma Agraria, aquéllas que se caracterizan por «la inversión del capital suplementario en gran escala, el régimen de trabajo asalariado y el empleo de medios técnicos modernos...» ${ }^{15}$. Esta clase de propiedad está «defendida por la letra y el espíritu del propio decreto de la reforma y [es], por tanto, "inafectable"» (Yawarninchij, p. 269). Este argumento, en líneas generales, sirvió como poderoso subterfugio bajo el cual se escudaron muchos terratenientes, con mayor o menor fortuna, para rescatar sus tierras. En todo caso, quizá los mayores beneficiarios de la Reforma Agraria fueron los abogados.

Yawarninchij, que se sitúa en los meses antes de la repartición de la tierra, nos muestra las vicisitudes del indio en espera de su parcela de tierra, el triunfo del Minero, que logra la sindicalización de las aldeas del valle, y más que todo hace que el campesino se sienta digno de los derechos que poco a poco va adquiriendo. El cambio psicológico que se opera entre los campesinos constituye el fundamento sólido de la revolución que se sucede a través de la trilogía. Los cambios se originan impulsados por una cefalía comunitaria, que incluye una junta de ancianos al lado de otra generación de jóvenes, futuros líderes de su pueblo.

${ }^{14}$ James M. Malloy y Richard S. Thorn, Beyond the Revolution: Bolivia Since 1952 (Pittsburgh: University of Pittsburgh Press, 1971), p. 245.

15 Arturo Urquidi, p. 196. 
En Sinchikay, la segunda novela de la trilogía, se toma la tierra y se fortifica la sindicalización de las comunidades indígenas. Para frenar estos: logros económicos y sociopolíticos de los campesinos, los antiguos terratenientes, por medio de poderosas influencias, montan una especie de contrarreforma. Por una parte, ellos disputan al indio la tenencia de la tierra, y por otra, el gobierno pretende centralizar todas las tierras afectadas antes: de otorgar los títulos de propiedad con un visible afán de lucro personal. Por estas razones valederas, los indios de Saipurenda deciden retomar, porsu propia cuenta, las antiguas haciendas de los patrones y detener la fuga de las cosechas. La incertidumbre de la posesión legal de la tierra se esclarece en el pasaje de Sinchikay, en el que se narra la entrega de títulos de propiedad. Se muestra a los colonos optimistas, puesto que, según el plano. del topógrafo, a cada familia le tocaba algo más de una fanega de tierra, extensión halagadora para los que antes no trabajaban más que sus miserables pegujales concedidos en usufructo. Los primeros títulos se entregan a los secuaces, que se hacen acreedores a seis hectáreas, mientras que a los: indios se les hace dueños de su pegujal, del que ya casi eran propietarios: antes de la Reforma Agraria. De ahí que un campesino, haciendo coro del. sentimiento de todos, dice:

¿Es éste el título que me cuesta tanto dinero en honorarios y coimas, tanto sudor, tanto ajetreo?... Para esto no necesitaba alimentar tantas: esperanzas, ni maniatarme con una cadena de deudas, ni perder tanto tiempo. Para seguir poseyendo el pegujal que siempre fue mío y para seguir matando de hambre a mis hijos, no necesito este título... (pp. 244-245).

Tan exigua extensión de tierra abastece solamente para una economía de autoconsumo, limitando al campesino en toda futura inquietud de desarrollo. Al encasillárselo dentro de un minifundismo, se le reduce su poder político y, consiguientemente, se le coarta en su crecimiento cultural, lo cual se hace patente aún hoy mismo, puesto que el campesino todavía no ha trascendido en gran manera su condición servil. Los eventos históricos justifican la narrativa de Lara, quien hace que la comunidad de Saipurenda no siga los dictámenes de la Reforma Agraria, sino que más: bien alienta a los campesinos para que ellos, por medio de la acción directa, ocupen las tierras de los antiguos patrones y gocen del beneficio de los granos que ellos mismos plantaron y cuidaron. En esta lucha, Saipurenda, que ha crecido física y psicológicamente, ha conservado su autonomía y sirve al escritor como un laboratorio donde ejercita la realización de una revolución económica y cultural. El propósito último de este novelista, al anatomizar una revolución, es concretar su «anhelo que tiende a conseguir 
que nuestro pueblo indígena adquiera la necesaria conciencia de clase y luche por salir de la postración económica, cultural y social en que se halla sumergido desde la llegada de Pizarro hasta el presente» ${ }^{16}$.

El programa revolucionario de Saipurenda da importancia vital a los beneficios de la educación. Pero la educación del indio, como inclusive hoy día se la imparte, tiene un efecto alienante. La educación escolar trata de incorporar al indio a la cultura occidental, privándole al mismo tiempo de la suya. Lara, que se da cuenta de que el indio tiene que convivir en una sociedad bilingüe, entonces propugna por una educación también bilinguie. Los líderes de Saipurenda, con excepción de los jefes ancianos, poseedores de una sabiduría milenaria, pasan por las aulas, transponen las barreras del idioma y descuellan sobre los otros por su estudio. La educación no sólo los capacita para superar su condición de explotados, sino que además representa la gran igualadora de los sexos. En su trilogía, Lara da un lugar prominente a la mujer: ella se halla siempre al lado de sus camaradas, tanto en la fortuna como en la adversidad. A través de su narrativa, sus personajes más logrados han sido las mujeres; desde mama Surumi, calificada como «un esfuerzo sin reposo, un padecimiento sin alivio, un sacrifico sin recompensa...», pasando por aquel impulso vital que es Wayra, el dinamismo carismático de Miquita, la abnegación de Vinvela, para terminar con la «Brigada de Choque», escuadrón aguerrido de mujeres que se entregan a la lucha a la par que los varones. Los personajes femeninos de esta trilogía alcanzan posiciones de importancia gracias a su propio esfuerzo. Dicho sea de paso, Lara es el precursor de la inexistente literatura feminista en Bolivia, exceptuando, claro, la poesía de Adela Zamudio.

El novelista hace de Saipurenda un centro abiertamente comunista, donde la toma de conciencia del campesino está destinada a la abolición del conflicto de clases, a la desaparición de explotados y explotadores. En contra de esta forma de vida se encuentran, una vez más, el Gobierno y la Iglesia: el primero intenta frenar las reformas y su interferencia suscita numerosos hechos de sangre contra los que Saipurenda tiene que defenderse, a pesar de que su política es la de una resistencia pacífica. La Iglesia, por su parte, participa en la prolongación de la explotación en el campo como otro capitalista más y como aliada de los gobiernos imperialistas. Para lograr sus fines, se vale de la mentira, la calumnia y la agitación, todo destinado a destruir al odiado comunismo. A pesar de que el comportamiento del gobierno y el de sus aliados en contra de la actitud asumida por

${ }^{16}$ Alfonso Gumucio Dragón (ed.), «El compromiso inquebrantable: Jesús Lara», en Provocaciones (La Paz: Los Amigos del Libro, 1977), p. 158. 
los de Saipurenda está perfectamente motivada a través de la narrativa, adquiriendo ésta una cualidad de verosímil, la escisión de ambas posiciones pecan, la una, por su extremada bondad, su equilibrado pensar y su buen obrar, y la otra, por la sevicia de sus actos. En ambos casos, por su acercamiento maniqueísta, el autor cae en la caricatura.

En Sinchikay se ve a los indios conscientes ya de sus derechos, armados de un remozado valor y adaptados a la nueva percepción que tienen de ellos mismos. En esta novela se avanza la revolución, puesto que ahora los de la comunidad consideran que la tierra ya no es un fin, sino otro medio más en la lucha hacia su liberación total. Por eso Rafitu, el maestro, haciéndose portavoz de todo el pueblo, arenga a sus camaradas diciendo:

... nuestra lucha no ha terminado todavía. Hemos conquistado la tierra, pero la tierra no es todo. Tenemos que seguir luchando hasta conquistar una vida nueva, hasta sentirnos verdaderamente libres y disponer de nosotros como nos convenga (p. 339).

Este objetivo final está narrado en Llalliypacha ${ }^{17}$, donde se trata de consolidar el dominio de la tierra. Esta novela ata los cabos argumentales de las dos previas con el fin de crear un todo coherente y dar un sentido concluyente al mundo narrativo. A este propósito contribuye el retorno a Saipurenda de varios personajes, emisarios que salieron de esta comunidad para propagar la revolución total de la sociedad boliviana.

A pesar de que ha pasado casi una década desde la reforma agraria, en la ficción los enemigos de la clase campesina todavía pretenden encasillarlos dentro de una condición servil y, así, frenar las conquistas sociales obtenidas. La tesis de Lara deja entrever que la explotación del indio no ha cambiado, sólo que los amos son otros: los terratenientes y los mayordomos son sustituidos por los nuevos dirigentes políticos; el sistema judicial sigue defendiendo los intereses de su casta y la Iglesia sigue apoyando a los poderosos. Llalliypacha, entonces, narra la larga y agotadora lucha de trincheras que tiene que sostener Saipurenda por dos años para consolidar su poder. Al final de las escaramuzas se hace la paz, al haber las huestes campesinas derrotado al ejército del gobierno por su mala organización y la ineptitud de sus jefes. Pero, al poco tiempo de haber durado el armisticio, los jefes del pueblo son asesinados uno a uno; además, las múltiples promesas rotas por los militares, que ahora son dueños del país, hacen pensar que esa paz no es duradera. De aquí emerge otro mensaje del novelista: para sobrevivir y mantener los derechos ganados, el pueblo indio nunca debe dejar de vigilar el desarrollo de su cultura ante los seguros

${ }^{17}$ Jesús Lara, Llalliypacha (La Paz: Los Amigos del Libro, 1965, 2. ed., 1977). 
avances que tienden a su destrucción. La lucha no ha terminado, sino que continúa...

En el resto de este estudio haré una crítica global de las novelas analizadas e intentaré situar a Jesús Lara dentro de la literatura indigenista hispanoamericana. Primeramente, y siguiendo la tesis de Mariátegui, Lara también considera que el problema del indio se fundamenta en la tenencia de la tierra y, por tanto, debe ser considerado con arreglo a una realidad económica, social, política y no racial. Para él, el indio se halla subyugado al no participar en todos los aspectos de la producción agrícola y al hecho de que el indio se halla disociado de la tierra. Lo que el autor objeta de los terratenientes, blancos o mestizos, no es el tinte de su piel, sino el hecho de que ellos, por el poder económico que ostentan, disponen de los poderes judiciales para prolongar la condición servil del indio y perpetuar su posición de privilegio. El factor racial es descartado en tanto se evidencia que algunos mestizos o indios aculturados, en sus papeles de mayordomos o caciques, por congraciarse e imitar a los blancos, son los que castigan al indio con mayor sevicia, olvidándose del vínculo de consanguinidad.

Para lograr la posesión de la tierra por el indio y la destrucción del sistema feudal, en la «trilogía de la revolución agraria», Lara se vale de militantes salidos del medio indígena, puesto que sólo ellos, por la mentalidad y el idioma, pueden conseguir un ascendiente eficaz e inmediato sobre los de su clase ${ }^{18}$. Estos indios aculturados que vuelven a sus predios, como Wáskar Puma, el Minero, Miquita y otros, ya no son más aquellos indios milenarios, estoicos, subyugados y muchas veces resignados con su suerte, sino que son instruidos, conscientes de sus derechos y orgullosos de su tradición. Ellos regresan dispuestos a dirigir a sus hermanos de sangre en la obtención de una sociedad donđe no se haga distinción de clases. Armados con las doctrinas marxistas, estos nuevos jefes indígenas pretenden rescatar su antigua cultura olvidada, aspiran a reconstruir sobre la base de una economía socialista incaica, sobre la jerarquía de una cefalía comunitaria. El cambio psicológico operado en los indios de Saipurenda se debe precisamente a la educación bilinguie que reciben, al énfasis en el conocimiento de la tradición quechua, factores que activan la posterior toma de conciencia revolucionaria.

La indignación ética del autor ante la injusta situación del indio y su deseo de cambiar su estado de postración encuentran en Jesús Lara una solución: el mestizaje cultural. El indigenista boliviano sostiene que antes y después de la reforma agraria la antigua trinidad explotadora, el poder

${ }^{18}$ José Carlos Mariátegui, Ideología y política, p. 45. Citado de Eugenio ChangRodríguez, «E1 indigenismo peruano y Mariátegui», p. 390. 
político, el religioso y el económico, seguía actuando en detrimento de un vasto estrato social subyugado. Para contrarrestar este poder, promulga una revolución marxista. Sin embargo, los conductores de dicha revolución, los nuevos jefes naturales de los indios, parecen hombres alienados que han perdido sus características raciales. Si se sopesa el tono de Surumi y Yanakuna con el de la trilogía, que cae más dentro del género del realismo social, se vislumbran marcadas diferencias no sólo temáticamente, sino también en su calidad estética: las primeras novelas son de mayor valor literario. Yanakuna, por ejemplo, pone en evidencia el nexo panteístico que existe entre el indio y la tierra, la Pachamama, que como una verdadera madre sustenta a sus hijos a cambio de su deificación. Mientras que en la trilogía la tierra adquiere una dimensión diferente: ella es vista en términos de fuerza productiva; su valor es ahora estrictamente de índole económico. Ya no se nota aquel apego telúrico, aquella «mística de la tierra», por utilizar el término de Guillermo Francovich.

En la trilogía no hay una búsqueda de la esencia de la totalidad de la cultura nacional, base de la única autenticidad posible; de ahí que estas novelas se centren más en el pasado histórico que mítico de la cultura indígena ${ }^{19}$. Se pone de manifiesto más bien una ruptura entre la relación de la naturaleza y la religión, y la narración ya no se detiene para mostrarnos los múltiples detalles que hacen que una cultura sea única, elementos que son el fundamento de los mundos narrativos de, por ejemplo, Los ríos profundos, de José María Arguedas. Al contrario, la trilogía se lee más como novelas de tesis $\mathrm{y}$, podría decirse, cae fuera del estricto ámbito de la literatura neoindigenista, que se caracteriza, entre otras, por el «realismo mágico» y la intensificación del lirismo ${ }^{20}$. En vez de delinearse la polifacética realidad cultural indígena, se nos presenta la visión esperanzada que el autor quisiera para los indios. Lara depone el mito para sustituirlo por el marxismo: armado con esta doctrina no pretende incorporar al indio dentro de la vida nacional, sino más bien lo aísla del resto de la sociedad. Al ver el fracaso de la revolución nacional y el resurgimiento mimetizado de la antigua trinidad explotadora, Lara crea un núcleo revolucionario que espera sea la antorcha que prenda el fuego marxista que cambie la esencia misma del país. En este sentido, Lara está más cerca de la novelística de

19 Juan Manuel Marcos, «La ternura pensativa de José María Arguedas», en Revista Iberoamericana, 50, 127 (abril-junio 1984), p. 453.

${ }^{20}$ Antonio Cornejo Polar, «Sobre el 'neoindigenismo' y las novelas de Manuel Scorza», en Revista Iberoamericana, 50, 127 (abril-junio 1984), p. 549. Consúltese también el artículo de Antonio Urello, «Antecedentes del neoindigenismo», en Cuadernos Hispanoamericanos, núm. 268 (octubre 1972), pp. 5-25. 
Manuel Scorza, quien también propone que la concepción de la revolución indigenista necesita el soporte de una racionalidad moderna y pragmática ${ }^{21}$. Dentro de esta praxis, Lara concibe que la revolución agraria es una parte más de la revolución total del proletariado. A este fin apuntan los múltiples emisarios que salen y entran en Saipurenda para crear una red de organización revolucionaria. El indio conductor de esta revolución es un hombre nuevo, hecho de la misma fibra aguerrida de los personajes de su libro de relatos, Nancahuasú: Sueños, narraciones sobre las guerrillas, y que constituye otro capítulo más que intenta contribuir a la revolución del proletariado boliviano ${ }^{22}$.

Como Lara tiene un programa revolucionario a seguir, sus personajes están adecuados para llevar a cabo tales propósitos. Una comparación de los personajes de la trilogía con los de otras novelas indigenistas deja el siguiente saldo: en términos generales, los personajes de la trilogía no poseen una compleja psicología, parecen no tener conflictos internos, sino la idea fija de la meta a la que quieren llegar - que no está exenta de pentrias-y de saber la manera más propicia de lograrlo. Si comparamos a Demetrio Rendón Willka con el Minero, ambos indios aculturados, notamos en éste una serie de cualidades superlativas como su valor, su cultura, su don de palabra y el de enseñar por medio del ejemplo. Armado con el conocimiento de un sistema revolucionario científico, está determinado fatalísticamente a contribuir al éxito de su empresa; todas sus acciones están subordinadas a la tesis de las novelas. En cambio, Rendón Willka se caracteriza por una despierta pero cautelosa inteligencia; él observa, asimila y analiza pacientemente la contextura histórica del momento y la yuxtapone a la realidad arcaica de su comunidad antes de decidirse por una determinada acción. Este personaje introspectivo, al posponer su decisión hasta el momento propicio, adquiere un carácter ambiguo, y precisamente la falta de un perfil nítidamente delineado es lo que le hace intrigante, más real, más humano.

Dentro de la misma narrativa de Jesús Lara se notan marcadas diferencias entre la concepción de los personajes de Yanakuna, Surumi y los

\footnotetext{
${ }^{21}$ Antonio Cornejo Polar, p. 555.

${ }^{22}$ Lara no sólo apoyó moralmente a estas acciones armadas, sino que también perdió, en una de ellas, a su hijo político. Como homenaje póstumo, transcribe las experiencias de éste en Guerrillero Inti Peredo. Tres mil copias de este libro fueron incineradas por las fuerzas policiales y en 1980 aparece una edición costeada por Jesús Lara. Este relato y Ñancahuasú: Sueños son someramente analizados por José Ortega en el capítulo dedicado a Jesús Lara, «La épica de la guerrilla boliviana. Nancahuasú», en Temas sobre la moderna narrativa boliviana (La Paz: Los Amigos del Libro, 1973), pp. 89-99.
} 
de la trilogía. En las primeras, tanto Wáskar Puma como Wayra son personajes de intrincada psicología, de múltiples recursos, que evolucionan y crecen como resultado de la interacción de su realidad interior y la influencia externa. Como tal, entonces, son personajes redondos o llenos, con temores, amores, alegrías y penas y que se definen, en última instancia, por sus acciones. Mientras que los personajes de la trilogía son planos, es decir, unidimensionales, a pesar de estar sus acciones bien motivadas. Ellos están congelados en «tipos»; por ejemplo, el Minero es el teórico de la revolución; Miquita, la propulsora de la misma, y así sucesivamente. Estos guías espirituales de Saipurenda poseen un cúmulo de cualidades, como el desprendimiento de las cosas materiales, la falta de egoísmo, una sólida cultura y la capacidad de transmitir sus ideas y de mover a su gente hacia la acción; ellos poseen todas estas cualidades en grado superlativo, rara vez se equivocan. Los héroes de Saipurenda parecen vaciados de un molde rousseauniano, idealizados; son como los caballeros andantes: aguerridos, fieros y valientes en la lucha; torpes, incoherentes y tímidos ante sus damas, indias de sin par belleza y óptimas cualidades. Mientras que los adversarios de este pueblo son unos hedonistas, sanguinarios y cobardes. De ahí que el juego maniqueísta es manifiesto. En general, todos estos personajes no valen por sí, sino que existen en función de una idea. Razón por la cual, por su excesivo afán de engrandecer a unos y disminuir a otros, el autor cae en la caricatura al deformar la realidad.

Sin embargo, Jesús Lara también ha creado verídicos personajes. Por ejemplo, Wayra, la heroína de Yanakuna, es un personaje inolvidable: motivada por un deseo desesperado de libertad, provista de una energía inagotable, andariega infatigable, nos lleva junto a ella para mostrarnos sus trajines, su vida tan llena de sacrificios y penurias y tan escasa de alegrías. En este personaje coexisten tanto el odio, el rencor, como el agradecimiento y la ternura; es frágil e ingenua para el amor, y puede ser arrastrada por la compasión, así como reaccionar como una fiera herida para defender lo que es suyo. Tantos sentimientos contradictorios y de gran carga emocional se mezclan armónicamente en ella, tal como sucede en la vida real, razón por la cual Wayra vive, respira y palpita en cada página. Anotemos de pasada que este personaje está inspirado en la vida de una campesina que contó al autor su ciclo de tribulaciones. Inclusive, el Wáskar Puma de Surumi es más complejo, más humano, que el revolucionario Wáskar Puma de la trilogía. Este personaje, en la primera novela de Lara, experimenta la confusión, el miedo y la ansiedad de aquellos que se ven transportados a extraños ambientes. Los cambios psicológicos que se operan en este joven estudiante, influido siempre por temores y odios ancestrales, muestran muy bien el proceso del lento mestizaje que ocurre en el 
indio que llega por primera vez a la ciudad y que asimila con bastante dificultad un idioma extranjero, otros modos de ser y una cultura diferente a la suya.

Jesús Lara, al inclinarse por la solución socialista ${ }^{23}$ al problema del indio, deja de lado su identificación personal con la cosmovisión indígena para diagramar los rescoldos polifacéticos de toda una revolución, y lo hace a través de una prosa límpida y castellana, salpicada a veces por locuciones quechuas. Inclusive el lenguaje de Lara lo acusa de la necesidad que él siente por la modernización de la sociedad indígena. A pesar de su afinidad étnica y su afectividad cultural con los indios, no pudo evitar ni resolver el dilema del escritor indigenista de ver a su propio pueblo desde otra cultura y «nombrarlo» desde otra lengua ${ }^{24}$. Al encontrarse en la encrucijada de dos lenguas y de dos culturas, opta por la revolución marxista de ambas sociedades. La transformación que experimenta la comunidad de Saipurenda es tan radical, que en Llalliypacha apenas sí se puede reconocer a los indios de Yawarninchij, la primera novela de la trilogía. Este aguerrido pueblo, al descartar el impulso revolucionario mítico indígena, del que Rosario Castellanos hiciera tanto uso en Oficio de tinieblas, se ha alienado de sus raíces culturales, por lo que la revolución efectuada recusa como redime esa cultura. Al darse más importancia a la revolución, la novelística de Lara se sitúa más concretamente en el plano del conflicto que de la definición ${ }^{25}$. Toda su narrativa parece responder a la sentencia de que Ciro Alegría deja constancia en El mundo es ancho y ajeno, que la cultura no puede estar desligada de un concepto operante de justicia y que ésta sea acción y no sólo principio ${ }^{26}$. Así fue como Lara ofrendó su pluma

${ }^{23}$ Braulio Muñoz hace una diferencia entre la solución liberal y la solución socialista al problema indígena: para el escritor liberal, fuerzas foráneas liberarían al indio de su estado servil al incorporarlo en la sociedad sin cambiar drásticamente la esencia de la comunidad patrocinadora. Este acercamiento considera más la participación del indio en la economía capitalista que el valor de la vida comunitaria indígena. En cambio, el escritor socialista considera que el indio mismo es el artífice de su propia revolución, y que su vigor y espíritu revolucionario se encuentran en su cultura ancestral misma. Por esta razón, el escritor socialista se empeña en privilegiar la cosmovisión indígena. Sons of the Wind. The Search for Identity in Spanish-American Indian Literature (New Brunswick, New Jersey: Rutgers University Press, 1982), pp. 137-150. De acuerdo con esta división, Lara se encontraría en una situación intermedia entre ambas posiciones.

${ }^{24}$ Ester Gimbernat de González, «Arguedas: Mito e ideología», en Revista lberoamericana, 49, 122 (enero-marzo 1983), p. 204.

${ }^{25}$ Noé Jitrik, «Arguedas: Reflexiones y aproximaciones», en Revista Iberoamericana, 49, 122 (enero-marzo 1983), p. 89.

${ }^{26}$ Ciro Alegría, El mundo es ancho y ajeno (Buenos Aires: Losada, 5. ed., 1971), p. 455. 
al compromiso social con su pueblo, sacrificando la calidad estética de su literatura por la permanencia de los valores éticos.

Sin embargo, y a manera de conclusión, digamos que Jesús Lara es, entre los novelistas bolivianos, el que mejor ha captado la forma de vida, la psicología, los pesares y las aspiraciones de los indios quechuas del valle cochabambino. Por medio de su narrativa puede reconstruirse la historia de las grandes corrientes que transformaron la fisonomía de Bolivia en el último medio siglo. A través de sus novelas se capta lo que Unamuno llama la intrahistoria, la historia de los no historiables, la travesía vital de un pueblo. En la época anterior a la Reforma Agraria, los lectores somos testigos de la explotación, el escarnio y la impotencia diaria del indio tratando de sobrevivir ante la incertidumbre de su futuro. Acompañamos a un pueblo en su lucha por la tenencia de la tierra como base para su futura liberación; todo esto por medio de una prosa límpida y cuidadosa, de un plan cuidadosamente concebido y pensado. Su trilogía se caracteriza por una narración tupida, rica en eventos y circunstancias que muestran uno y mil detalles de la anatomía de una revolución y el resurgir de todo un pueblo; el protagonista es siempre el pueblo, al que vemos metamorfosearse desde mil ángulos diferentes. Por esta razón, y en general, toda la novelística de Jesús Lara adquiere proporciones épicas. Cabe anotar que este autor posee una sutil ironía: es perspicaz y acre en su oportuno sarcasmo y toda su prosa está secundada por un delicioso humor que demuestra su capacidad de sonreír en el infortunio. 
